OAK RIDGE

NATIONAL LABORATORY

MANAGED BY UT-BATTELLE

FOR THE DEPARTMENT OF ENERGY
ORNL 98-0538

Metals and Ceramics Division

CRADA Final Report

For CRADA Number ORNL 98-0538

Diffusion Resistant, High-Purity

Wafer Carriers For SI

Semiconductor Production

T. N. Tiegs

Oak Ridge National Laboratory

L. Leaskey

Materials Focus, Inc.

Date Published - October 2000

Prepared by the

OAK RIDGE NATIONAL LABORATORY

Oak Ridge, TN 37831

managed by

UT-BATTELLE, LLC

for the

U.S. Department of Energy

under contract DE-AC05-00OR22725

APPROVED FOR PUBLIC RELEASE

UNLIMITED DISTRIBUTION 
Metals and Ceramics Division

CRADA FINAL REPORT

FOR

CRADA NO. ORNL 98-0538

\title{
DIFFUSION RESISTANT, HIGH-PURITY WAFER CARRIERS FOR SI SEMICONDUCTOR PRODUCTION*
}

\author{
T. N. TIEGS \\ OAK RIDGE NATIONAL LABORATORY \\ L. LEASKEY \\ MATERIALS FOCUS, INC.
}

Date Published - October 2000

Prepared by the
Oak Ridge National Laboratory

Oak Ridge, TN 37831

Managed by

UT-Battelle, LLC

For the U. S. Department of Energy

under contract DE-AC05-00OR22725

Approved for Public Release

Unlimited Distribution

\footnotetext{
"This research was supported through a CRADA with Materials Focus, Inc., Tucson, AZ, sponsored by the Laboratory Technology Research Program, Office of Science, U. S. Department of Energy, under contract DE-AC0500OR22725 with Oak Ridge National Laboratory, managed by UT-Battelle, LLC.
} 


\begin{abstract}
The Cooperative Research and Development Agreement (CRADA) was directed towards development of diffusion resistant, high-purity wafer carricrs for $\mathrm{Si}$ semiconductor production with improved properties compared to current materials. The determination of the infiltration behavior is important for controlling the fabrication process to obtain consistent high-quality products. Ammonium molybdate or molybdenum carbide were found to be suitable as a precursor to produce $\mathrm{SiC}-\mathrm{MoSi}_{2}-\mathrm{Si}$ composites by $\mathrm{Si}$ infiltration into carbon preforms. Experiments on the pyrolysis of the preforms showed variable infiltration behavior by the molten $\mathrm{Si}$ (within the range of conditions in the present study). Further research is required to reproducibly and consistently fabricate flaw-free articles. The strength of the composites fabricated to-date was $325 \pm 124 \mathrm{MPa}$, which is higher than current commercial products. Better process control should result in higher average strengths and reduce the variability.
\end{abstract}

\title{
CRADA OBJECTIVES
}

The purpose of the Cooperative Research and Development Agreement (CRADA) was to develop diffusion resistant, high-purity wafer carriers for $\mathrm{Si}$ semiconductor production that are superior to currently available materials.

\section{CRADA BENEFIT TO DOE}

The CRADA contributed to the development of potential advanced semiconductor products in the U. S.

\section{TECHNICAL DISCUSSION}

\section{Introduction}

The purpose of the Cooperative Research and Development Agreement (CRADA) was to develop diffusion resistant, high-purity wafer carriers for $\mathrm{Si}$ semiconductor production that are superior to currently available materials. Semiconductor devices are fabricated from high purity, single crystal silicon (Si) wafers which undergo several processing steps. It is critical that the Si wafers maintain their ultrahigh purity to optimize performance, since the introduction of even minute quantities of undesirable metallic contaminants into the Si wafers during fabrication is a major cause of device degradation and instability. Typical contaminants include $\mathrm{Fe}, \mathrm{Ni}, \mathrm{V}, \mathrm{Ca}, \mathrm{Cr}, \mathrm{Mg}$, and $\mathrm{Cu}$. In particular, $\mathrm{Na}$ contamination, often originating from human contact with the wafers, is a serious problem thought to be most often responsible for the failure of devices due to surface leakage. Advancing IC performance requirements and smaller feature size has led to increased recognition of the importance of eliminating any contamination of the Si wafers. This means that the environment in which the processing takes place must be ultrapure to prevent in-situ contamination of undesirable elements. Such purity requirements extend to the wafer carriers utilized in the oxidizing/doping diffusion processes which involve rapid heating and cooling cycles generally between $400^{\circ} \mathrm{C}$ and $1350^{\circ} \mathrm{C}$. In fact, these diffusion components have been identified as a major source of metallic contamination. Higher purity diffusion components are in demand, and this demand will certainly increase as technology advancements are made which require Si wafers with even more precisely controlled impurity tolerance levels.

In addition to more stringent purity requirements, it is likely that wafer carriers with improved mechanical properties will become critical for advanced technologies in which larger and heavier wafers are being produced. It is expected that $300 \mathrm{~mm}$ wafers (in comparison to the $200 \mathrm{~mm}$ wafers now being manufactured) will be the products of the future. Current wafer carriers made of $\mathrm{SiC}-\mathrm{Si}$ have very low strength, which deteriorates even further at the elevated temperatures used in the doping process. Improved high temperature strength will become important as higher 
processing temperatures approaching the melting point of Si are utilized, resulting in the need for a new composite with superior mechanical properties.

Significant cost reductions are possible due to the potential elimination of expensive SiC coatings currently utilized to improve long term purity. Also, higher strength products will decrease the frequency of product replacement due to premature fracture of these components and any product losses incurred during these failures. Perhaps the greatest impact on the semiconductor industry would be the increased number of high quality Si wafers, which could result in the development of higher performance semiconductor components giving the U.S. an edge over foreign competitors.

The carriers upon which the Si wafers are placed have traditionally been composed of polysilicon or quartz. However, these are increasingly being replaced by silicon carbide-silicon ( $\mathrm{SiC}-\mathrm{Si}$ )based components due to both, their higher temperature chemical and mechanical stability, and reduced risk of $\mathrm{Na}$ contamination. Current $\mathrm{SiC}-\mathrm{Si}$ components range in density to as low as $80 \%$ (depending on the fabrication process) and have the open porosity sealed by a final CVD-SiC step. This results in materials with relatively low strength and possibly containing some residual Si.

It is believed that an improved product could be offered by replacing the Si component with one more resistant to diffusion of metallic elements. Although electronic grade Si $199.9999 \%$ purity or better) is often used to fabricate the current wafer carriers, the Si component becomes contaminated due to multiple exposure to metals during processing or through diffusion of dopants used in $\mathrm{Si}$ wafer processing. These impurities become concentrated in the Si phase due to the higher diffusion of metallic species in $\mathrm{Si}$ as compared to $\mathrm{SiC}$. Thus, in terms of purity requirements for $\mathrm{SiC}-\mathrm{Si}$ diffusion components, it is desirable to eliminate all residual Si. Another drawback to the presence of $\mathrm{Si}$ is that the acidic cleaning solution for the diffusion components between doping runs tends to corrode the $\mathrm{Si}$, which weakens the wafer carrier and leads to particulate contamination. The presence of porosity is undesirable as well, since the cleaning solutions tend to become trapped in the pores and become sources for contamination during subsequent wafer processing.

As processing temperatures increase, the diffusivity of contaminant ions increases and $\mathrm{Si}$ wafer purity levels decrease. SiC-Si components are known to cause contamination of Si wafers, such that the level of metallic impurities is still too high for future integrated circuit manufacturing requirements. High purity $\mathrm{CVD} \mathrm{SiC}$ coatings increase purity levels at the surface; however, these have a limited lifetime and tend to spall or crack to continually expose the siliconized bulk of the material. In addition, the coating process adds significant cost to these already very expensive products.

Under a National Science Foundation (NSF) Phase I SBIR effort, Materials Focus, Inc. investigated a "new" SiC-based composition in which the typically used Si component was replaced with a more diffusion resistant compound. Lower rates of diffusion of certain elements through $\mathrm{MoSi}_{2}$ compared to those reported for Si were observed. Most of the work involved determining the diffusion coefficients for $\mathrm{Fe}$ in polycrystalline $\mathrm{Si}$ and $\mathrm{MoSi}_{2}$. The lower diffusion rates were $\sim 30$ times higher for the diffusion through $\mathrm{Si}$ compared to $\mathrm{MoSi}_{2}$, thus supporting the hypothesis that longer term purity will be established for $\mathrm{SiC}-\mathrm{MoSi}_{2}$ compared to the currently used SiC-Si components. The achievement of only $\mathrm{SiC}$ and $\mathrm{MoSi}_{2}$ in the wafer carriers with no residual $\mathrm{Si}$ is dependent on controlled processing including graphite preform characteristics and uniform incorporation of $\mathrm{Si}$ and Mo metals which is the basis for the CRADA.

The CRADA was directed towards development of diffusion resistant, high-purity wafer carriers for $\mathrm{Si}$ semiconductor production with improved properties compared to current materials. The determination of the infiltration behavior is important for controlling the fabrication process to obtain consistent high-quality products. Additionally, the increased understanding of the processes would lead to improved infiltration techniques and consequently improved wafer carrier materials. 
Approach .

The overall fabrication technique to produce high purity $\mathrm{SiC}-\mathrm{MoSi}_{2}$ composites consists of two major tasks: (1) Produce porous graphite-Mo containing preforms and (2) Infiltrate preforms with silicon (Si) metal. During Si infiltration of the porous preform, the Si reacts preferentially with the graphite (or carbon) to form $\mathrm{SiC}$, and the residual Si reacts with the Mo component to form $\mathrm{MoSi}_{2}$. Control of both the preform fabrication and the metal infiltration is necessary for the achievement of crack-free $\mathrm{SiC}-\mathrm{MoSi}_{2}$ bodies. For the graphite-Mo preforms, there is a specific target density associated with the relative amounts of graphite and Mo in the preform which will result in no residual $\mathrm{Si}$ and for which optimum final composite properties will be achieved. In addition, the pore structure of the porous preform must be such that infiltration occurs to completion. The work involved the fabrication of $\mathrm{SiC}-\mathrm{MoSi}_{2}$ composites initially as samples $(\sim 2 \times 2 \times 1 / 2 ")$ for complete evaluation of density, microstructure, phase distribution, purity, and ambient and elevated temperature mechanical properties.

The activities focused on producing graphite-Mo porous preforms using either of two different Mo sources: (1) ammonium molybdate [chemical formula $\left(\mathrm{NH}_{4}\right)_{6} \mathrm{Mo}_{7} \mathrm{O}_{24} \cdot \mathrm{xH}_{2} \mathrm{O}$ ] or (2) molybdenum carbide $\left(\mathrm{Mo}_{2} \mathrm{C}\right)$. Clearly, the $\mathrm{Mo}_{2} \mathrm{C}$ containing graphite preform will consist of $\mathrm{Mo}_{2} \mathrm{C}$ and graphite after pyrolysis. The ammonium molybdate component in the other preform transforms to $\mathrm{Mo}_{2} \mathrm{C}$ after pyrolysis, thus also resulting in a $\mathrm{Mo}_{2} \mathrm{C}$ - graphite porous preform. The advantage of the ammonium molybdate preform is the possibility of improved dispersion compared to the $\mathrm{Mo}_{2} \mathrm{C}$ preform.

\section{$\underline{\text { Results }}$}

Composites Produced With Ammonium Molybdate - X-ray diffraction results (Fig. 1) showed that the phases present in the graphite-ammonium molybdate preform after pyrolysis at $800^{\circ} \mathrm{C}$ were graphite and molybdenum oxide $\left(\mathrm{MoO}_{2}\right)$. Further heat-treatment to $1150^{\circ} \mathrm{C}$ results in the formation of graphite and $\mathrm{Mo}_{2} \mathrm{C}$, as shown in the X-ray diffraction (XRD) spectrum in Figure 2. Thus, the $\mathrm{MoO}_{2}$ continued to react with $\mathrm{C}$ until no $\mathrm{MoO}_{2}$ was available for further reaction. Seven additional preforms of the compositions were subjected to XRD analyses and all of these showed conclusively the presence of graphite and $\mathrm{Mo}_{2} \mathrm{C}$.

There are numerous processing variables for this system, and those investigated include: (1) amount of ammonium molybdate in slurry, or final target composition, (2) solids loading in the slurry, (3) weight ratio of graphite to resin powders, and (4) pyrolysis heat cycle. Table 1 shows the samples fabricated, their densities, and the infiltration results of these materials. X-Ray diffraction after infiltration indicated that the final composition consisted of $\mathrm{SiC}, \mathrm{MoSi}_{2}$, and $\mathrm{Si}$ (Fig. 3).

Three different pyrolysis heat cycles were performed. All of these utilized heating rates of $1 \% \mathrm{~min}$, but differed in holding times and nitrogen gas flow rates. Schedule A had shorter holding times and a gas flow of $0.8 \mathrm{cfh}$. Schedule $\mathrm{C}$ had the same cycle as Schedule A but a lower gas flow of $0.2 \mathrm{cfh}$. Schedule B had longer holding times and a gas flow of $0.8 \mathrm{cfh}$.

The results are very difficult to interpret for several reasons. It has been determined that the microstructure and the density of the porous preform is extremely sensitive to slight variations in processing variables, especially the temperature of the slurries. This in turn affects the ease of infiltration and the ability to form crack-free composites. In general, it is obvious that higher porosities promote complete infiltration; however, the microstructure itself must also be amenable to molten metal infiltration. Optical inspection of the samples showed that even samples prepared under the same general conditions behave differently during the Si infiltration. For example, examination of two different samples of the $15 \% \mathrm{MoSi}_{2}$ target composition heat treated according to Schedule $\mathrm{C}$ shows that one sample had substantial infiltration while the other had no infiltration. The commercialization of these materials demands reproducibility of the composites, which is the 
focus of continuing research by MFI. Comprehensive sample data sheets were prepared for each slurry, including measurement of processing temperatures, slurry viscosities, and casting times.

Mercury porosimetry measurements were performed to provide insight into the pore size characteristics which are amenable to complete metal infiltration of the preform to result in stable, uncracked composites. Table 2 shows the results of this testing where the samples shown wcre prepared from the ammonium molybdate slurries and heat treated according to different schedules. It can be seen that a wide range of pore size distribution is possible, and that this can be controlled by starting compositions and pyrolysis cycles. This type of data will be instrumental, both for quality control and for identifying appropriate microstructures for successful metal infiltration.

Composites Produced With Molybdenum Carbide - Table 3 shows the summary of results for the samples prepared using the -325 mesh $\mathrm{Mo}_{2} \mathrm{C}$ powders. The same general processing technique used to process the ammonium molybdate samples was utilized, where the $\mathrm{Mo}_{2} \mathrm{C}$ powder was incorporated in the slurry in the first step. As shown, viscosities ranged from very low at 2.5 to moderate at 16.6. As the amount of graphite in the slurries increased, the viscosities increased. However, there is no clear relationship between slurry viscosity and preform density, mainly due to the sensitivity of the processing variables as discussed above.

Again, the samples which demonstrated the best performance during infiltration are the samples with the lower densities, typically less than $1 \mathrm{~g} / \mathrm{cc}$. Many samples were completely infiltrated but extensively cracked. Several samples also had areas which were blue and green in color; this could be attributed to the presence of molybdenum oxide.

Improved control over the processing variables must also be implemented for these composites before any meaningful data analyses can be performed. Thus, the objective of the research was to produce porous preforms with controlled density, microstructure, and porosity characteristics. This would allow for the identification of the composites which are most suitable for infiltration without creating cracks in the materials.

Development of Preform Microstructure - From the previous tests, it became evident that the starting preform microstructure was dominating the infiltration process and consequently, the ability to successfully fabricate flaw-free composites. Thus, a closer examination of the variables affecting preform fabrication was initiated.

The major obstacle to producing stable, crack-free $\mathrm{SiC}-\mathrm{MoSi}_{2}$ composites is the difficulty in achieving composites with the same characteristics, particularly microstructure and porosity, from different slip casting slurries. To be commercially viable, a high level of reproducibility must be attained. Since the successful fabrication of crack-free composites resulting from the metal infiltration is critically dependent upon the characteristics of the slip cast porous preform, it is essential that the slip casting process be controlled to the extent necessary to ensure the repeated fabrication of preforms with the same microstructural characteristics. Unexpectedly, it was found that the microstructure and density of the preforms are extremely sensitive to even very slight variations in processing variables, much more so than is generally observed in the slip casting of e.g., ceramic powder slurries. An example of the sensitivity of the process is that a temperature difference in the slurries of only two degrees changed the microstructure of the preform from one that could be infiltrated without cracking to one that failed catastrophically. Strict control over processing variables was implemented, such as temperature controlled milling and casting rooms, as well as precise measurement of variables such as milling rotation speed, slurry viscosity and temperature. Another critical observation was the importance of casting time on the ability to produce uniform composites. Casting times that are too lengthy yield preforms with regions of nonuniformity due to preferential settling of larger particles. On the other hand, casting times that are too short result in preforms with low densities that produce composites with less than the desired SiC contents. Two different suspension agents were investigated to prevent segregation of large sized particles and to vary casting times. 
The large number of potentially controlling or influencing process variables also contributes to the challenge of producing homogeneous composites. Thus, statistically designed experimental arrays were employed to establish which variables are most influential on the slip casting slurry properties and thus preform microstructural characteristics and density. The experiments were designed according to the Taguchi technique, which uses fractional factorial orthogonal arrays. The arrays are designed to distribute the variables in such a manner that analysis of variance (ANOVA) of the data allows one to determine the effect of any one variable on a property. It has the ability to examine multiple variables and to determine the percentage contribution of each variable as it influences the property of interest. These arrays have been shown to be extremely instrumental for the identification of important processing parameters in materials development and have been successfully applied to several materials systems for which there were so many variables that a full factorial experiment was impossible.

A Taguchi analysis follows a series of steps as follows: (1) Identify the important variables in the process, (2) Select a range of variables, (3) Determine the parameters to be evaluated, (4) Select a suitable orthogonal array for the test, (5) Conduct the experiment, and (6) Perform the data analysis using several equations which can be found in the references.

The F-test is a statistical tool that can provide a decision at some confidence level as to whether the estimates are significantly different. The F-test is basically a simple ratio of the sample variances. When the ratio is large, the sample variances are believed to be unequal at some confidence level (usually 90,95 or $99 \%$ ). These required F-test values significantly depend on the degrees of freedom associated with the sample variance in the numerator (usually the variable) and the denominator (usually the error). These values can be found in tables provided in statistical analysis books. Each combination of confidence level, degrees of freedom in the numerator, and degrees of freedom in the denominator has an F-test value associated with it.

The portion of the total variation observed in an experiment attributed to each factor is reflected in the percent contribution calculation. It indicates the relative power of a variable to reduce variation of the parameter being tested. If the variable is controlled precisely, then the percent contribution is low. If the observed range of variation is small, then the indication is that the factor is unimportant to the variation, the factor which really causes variation has been left out of the test, or the levels chosen for the test were too narrow. For situations when the Sum of Squares, Mean Squares and Percent Contribution for the error is large, the indications is that there may be other significant contributors to the variation that either were not considered in the experiment or that are attributable to common cause variation. Usually, for a Percent Contribution for the error in the range of $15 \%$ or less, it is assumed that no important variables affecting the parameter were omitted from the experiment. However, if the Percent Contribution for the error is high, i.e., $>50 \%$, this indicates one or more of several possibilities: (1) some important factors were omitted, (2) the experimental conditions were not controlled well, (3) the experimental conditions were not significantly different from one another, or (3) measurement error was excessive.

The results on the effect of processing variables on slurry characteristics and resultant preform density are shown in Tables 4 and 5 for $\mathrm{Mo}_{2} \mathrm{C}$ and ammonium molybdate containing slurries, respectively. The effects of five variables (i.e., amount of suspension agent, target final composition or amount of $\mathrm{MoSi}_{2}$, solids loading, ratio of graphite to resin powder, and amount of dispersant) were evaluated for their influence on slurry viscosity, casting time, and preform density, all of which essentially dictate the preform microstructure.

The results of the Taguchi analyses indicated that the governing parameters influencing the stated variables and/or the extent of this influence differed for each system, i.e. $\mathrm{Mo}_{2} \mathrm{C}$ or ammonium molybdate (AmMo) starting materials. This is especially the case for the slurries containing Veegum as a suspension aid, whereas the Castmate slurries for both systems had more similar results. For example, for each system with Castmate, the most important variables influencing 
viscosity were the amount of Castmate and the solids loading, and for casting time were the amount of $\mathrm{Mo}_{2} \mathrm{C}$ or ammonium molybdate and solids loading. For the $\mathrm{Mo}_{2} \mathrm{C}$ system with Castmate slurries, the density was most critically dependent ( $71.5 \%$ contribution) on the $\mathrm{Mo}_{2} \mathrm{C}$ content, and the same trend (70.1\%) was observed for $\mathrm{Mo}_{2} \mathrm{C}$ system with Veegum slurries. This would be expected due to the much higher density of $\mathrm{Mo}_{2} \mathrm{C}$ of $9.2 \mathrm{~g} / \mathrm{cc}$ compared with $\sim 2.0 \mathrm{~g} / \mathrm{cc}$ for graphite and $\sim 1.5 \mathrm{~g} / \mathrm{cc}$ for resin. There is no significant influence of the ammonium molybdate content in the AmMo system. This might be attributed to the much lower density of the molybdenum oxide decomposition product of $4.5 \mathrm{~g} / \mathrm{cc}$, although the Mo compound after complete heat treatment is also $\mathrm{Mo}_{2} \mathrm{C}$. It is possible that lower amounts of $\mathrm{Mo}_{2} \mathrm{C}$ remain in the preform, resulting in a lesser influence of the ammonium molybdate content. For the AmMo system using Veegum as the suspension aid, the density is most influenced by the amount of graphite $(37 \%)$ and the amount of dispersant (28\%), similar to the all carbon preforms prepared from only graphite and resin powders. There is no data presented for density of Castmate slurries in the AmMo system because of large number of samples were cracked and thus a complete data set could not be obtained.

Accordingly, it is clear that all of the parameters investigated have some influence on one or more of the investigated properties for each system. Through identification of the most important parameters, it was possible to tailor starting compositions to produce the desired $\mathrm{Mo}_{2} \mathrm{C}$ preforms. The desired preforms are those that result in complete conversion to $\mathrm{SiC}-\mathrm{MoSi}_{2}$ without cracking. Secondary is to produce preforms that result in $\mathrm{SiC}-\mathrm{MoSi}_{2}$ composites with the best mechanical performance at room temperature and high temperature.

Composite Mechanical Property Characterization - Room temperature flexural strength measurements were performed using the 4-point bend technique on samples fabricated using $\mathrm{Mo}_{2} \mathrm{C}$ and having a final target composition of $15 \% \mathrm{MoSi}_{2}$. Strength values ranged from $185 \mathrm{MPa}$ to 419 $\mathrm{MPa}$, with an average strength of $325 \mathrm{MPa} \pm 124 \mathrm{MPa}$. All of the values exceed that of Norton's comparable product, which is reported to be $170 \mathrm{MPa}$ and the average strength is nearly double that of the Norton product. The flexural strength on one sample tested at $1000^{\circ} \mathrm{C}$ (under argon) was $118 \mathrm{MPa}$.

Examination of the fracture surface (Figs. 4 and 5) revealed that the critical flaws were associated with "pools" of Si that develop during the infiltration process. It would be anticipated that average room temperature strength values in excess of $400 \mathrm{MPa}$ should be accomplished with the achievement of sample reproducibility. Higher strength values will be a significant improvement, particularly with the current trend of the semiconductor industry of processing larger and larger $\mathrm{Si}$ wafers, which translates to heavier wafer loads that the wafer carriers must accommodate.

\section{INVENTIONS}

None.

\section{COMMERCIALIZATION POSSIBILITIES}

Materials Focus, Inc. is pursuing commercialization of diffusion resistant, high-purity wafer carriers for $\mathrm{Si}$ semiconductor production by the processes similar to those studied in the CRADA.

\section{CONCLUSIONS}

Ammonium molybdate or molybdenum carbide can be used as a precursor to produce $\mathrm{SiC}-\mathrm{MoSi}_{2}-$ Si composites by Si infiltration into carbon preforms. Pyrolysis of the preforms (within the range of conditions in the present study) all showed variable infiltration behavior by the molten Si. Further research is required to reproducibly and consistently fabricate flaw-free articles. The strength of the composites fabricated to-date was $325 \pm 124 \mathrm{MPa}$, which is higher than current 
commercial products. Better process control should result in higher average strengths and reduce the variability.

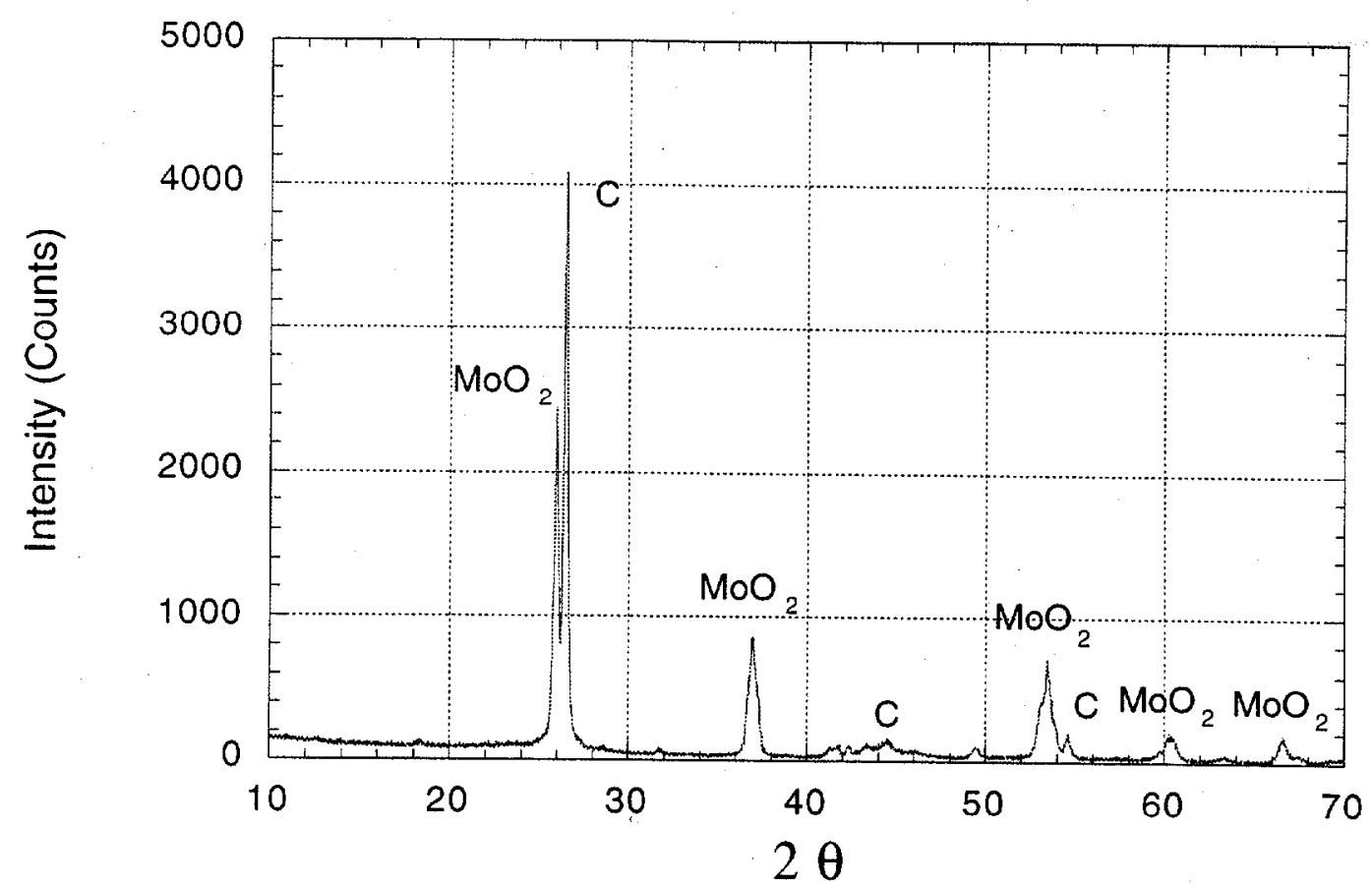

Fig. 1. X-ray diffraction of sample after heat-treatment to $800^{\circ} \mathrm{C}$. 


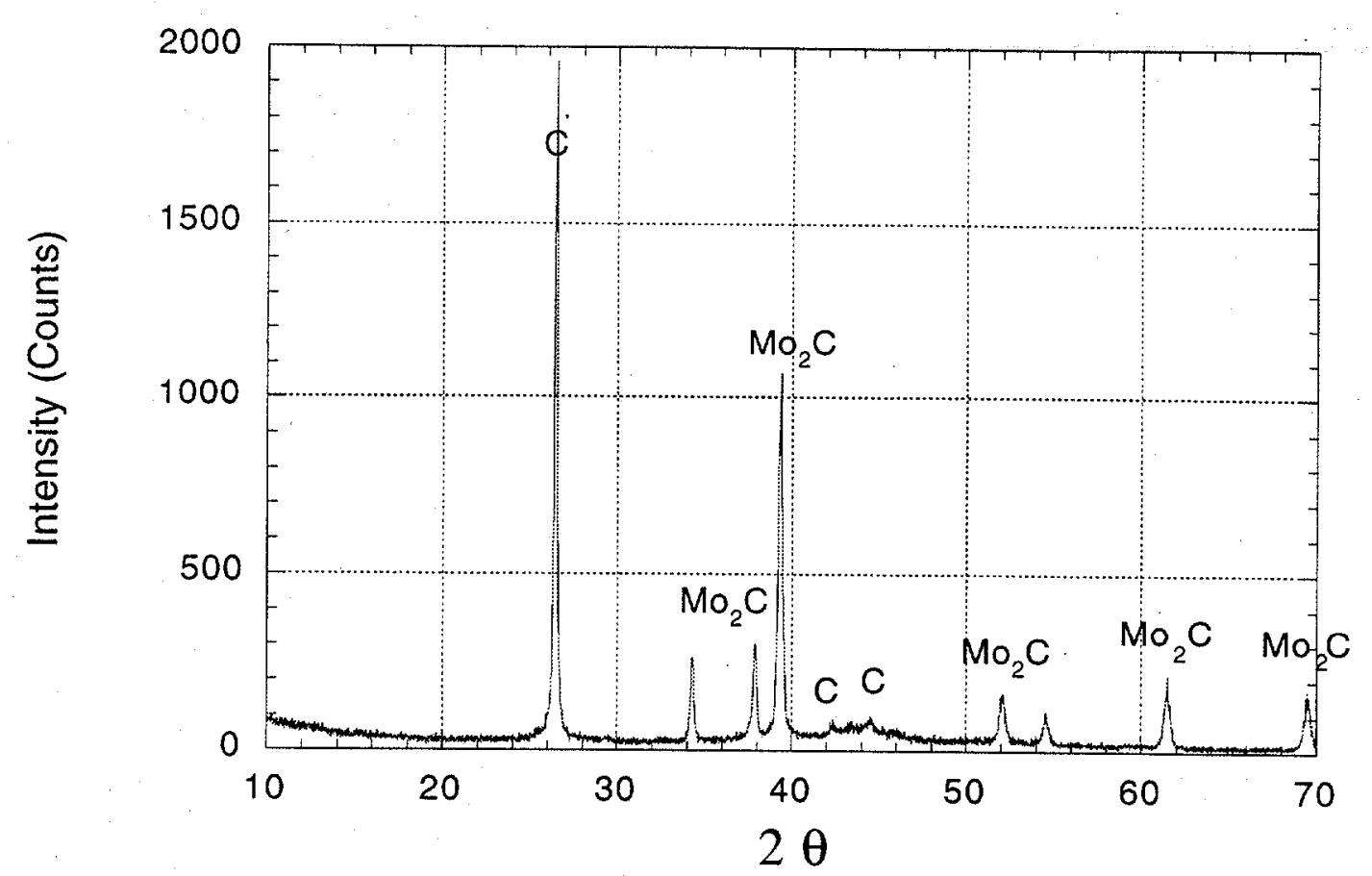

Fig. 2. X-ray diffraction of sample after heat-treatment to $1150^{\circ} \mathrm{C}$.

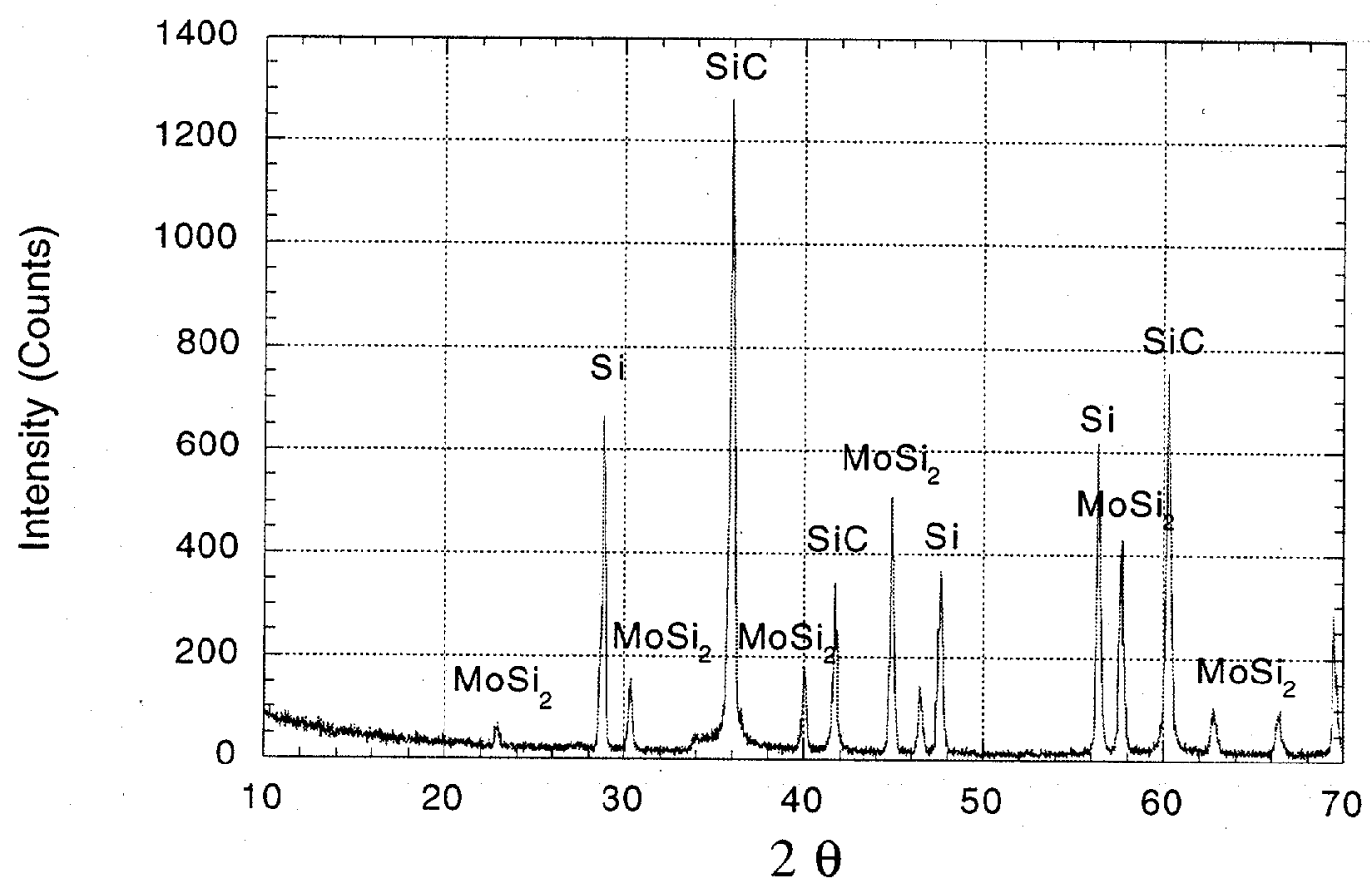

Fig. 3. X-ray diffraction of sample after heat-treatment to $1150^{\circ} \mathrm{C}$ and infiltration with molten $\mathrm{Si}$. 


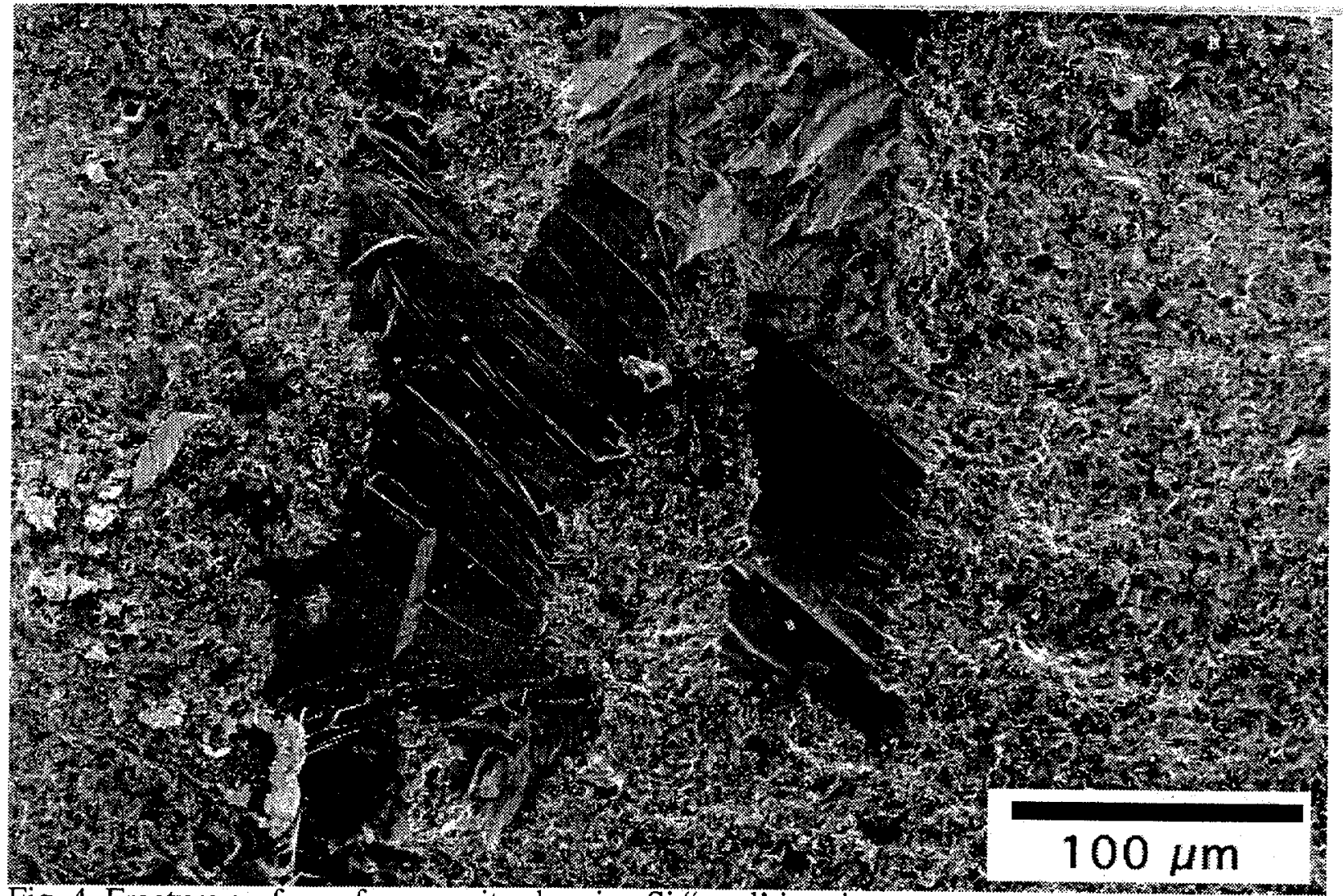

Fig. 4. Fracture surface of composite showing Si "pool' in microstructure.

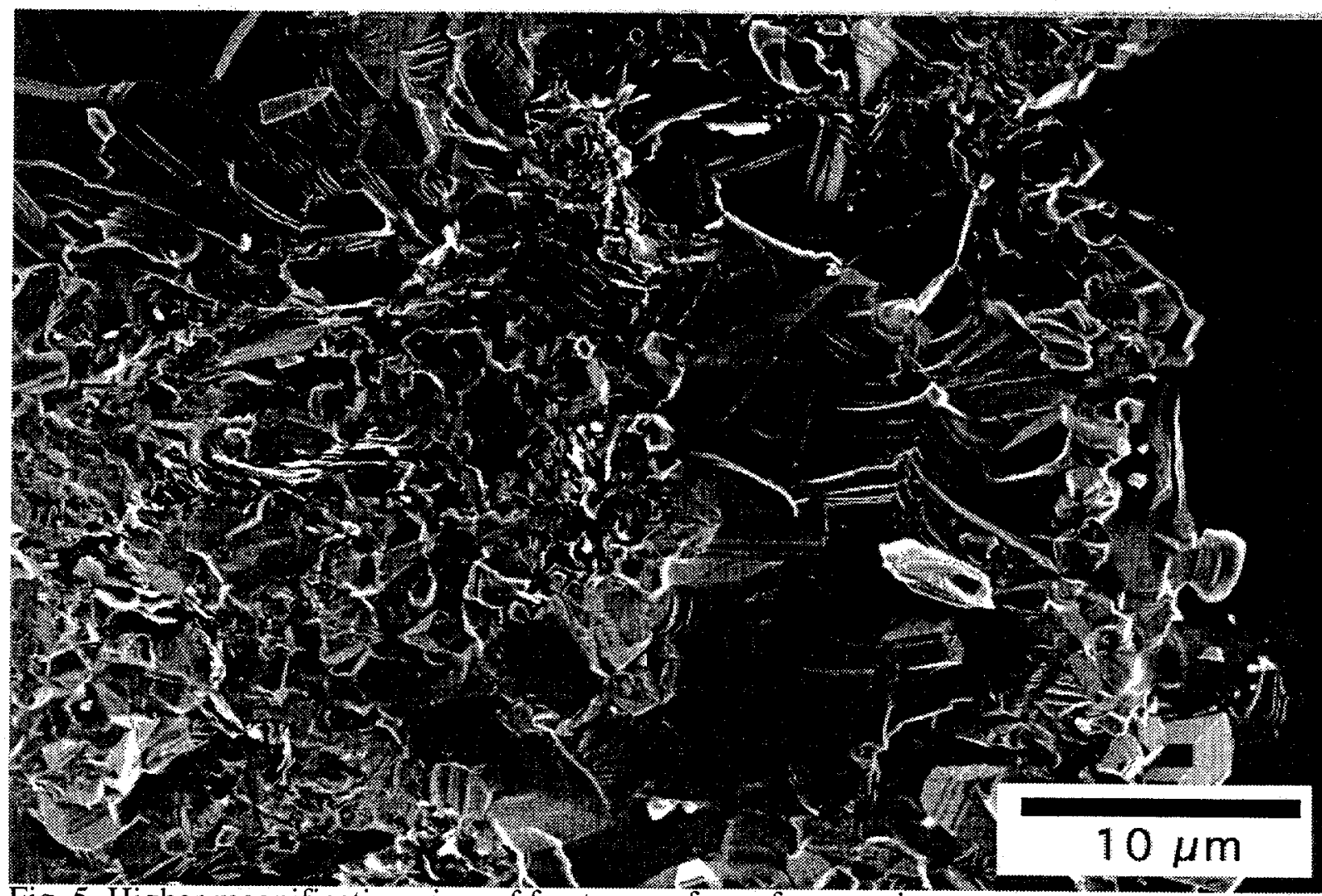

Fig. 5. Higher magnification view of fracture surface of composite. 
Table 1. Results of Molten Silicon Metal Infiltration for Samples Prepared with Ammonium Molybdate.

\begin{tabular}{|c|c|c|c|c|c|}
\hline $\begin{array}{l}\text { Sample } \\
\text { ID }\end{array}$ & $\begin{array}{l}\text { Final Target } \\
\text { Composition }\end{array}$ & Densit & $\begin{array}{l}(\mathrm{g} / \mathrm{cc}) \\
\mathrm{Sch}\end{array}$ & Sch. & Infiltration Results \\
\hline $\begin{array}{l}15-50 \% \\
(0.67: 1)\end{array}$ & $\begin{array}{l}15 \% \mathrm{MoSi}_{2}-85 \% \\
\mathrm{SiC}^{-85}\end{array}$ & 1.47 & 1.42 & 1.47 & $\begin{array}{l}\text { No infiltration except for one Sch. C sample, } \\
\text { which had extensive cracking. }\end{array}$ \\
\hline $\begin{array}{l}15-50 \% \\
(1: 1)\end{array}$ & “ & 1.22 & 1.14 & 1.20 & $\begin{array}{l}\text { No infiltration except for one Sch. C sample, } \\
\text { which had extensive cracking. }\end{array}$ \\
\hline $\begin{array}{l}15-50 \% \\
(1.5: 1)\end{array}$ & “ & 0.89 & 0.88 & 0.89 & No infiltration. \\
\hline $\begin{array}{l}20-34 \% \\
(1.27: 1) \\
\end{array}$ & $\begin{array}{l}20 \% \mathrm{MoSi}_{2}-80 \% \\
\mathrm{SiC}^{2}\end{array}$ & $\mathrm{~N} / \mathrm{D}$ & N/D & N/D & N/D \\
\hline $\begin{array}{l}20-40 \% \\
(1.27: 1)\end{array}$ & “ & 0.89 & 0.94 & 0.95 & $\begin{array}{l}\text { Sch. A and B samples were fairly good with } \\
\text { small areas not infiltrated. Sch. C samples were } \\
\text { fully infiltrated but had fine cracks. }\end{array}$ \\
\hline $\begin{array}{l}20-45 \% \\
(1.27: 1)\end{array}$ & “ & 0.85 & 0.90 & 1.04 & $\begin{array}{l}\text { Sch. A and B samples good but big center area } \\
\text { not infiltrated; Sch. C samples were fully } \\
\text { infiltrated but had fine cracks. }\end{array}$ \\
\hline $\begin{array}{l}20-50 \% \\
(0.67: 1)\end{array}$ & “ & 1.40 & 1.42 & 1.45 & $\begin{array}{l}\text { No infiltration except for one Sch. B sample, } \\
\text { which had fine cracks. }\end{array}$ \\
\hline $\begin{array}{l}20-50 \% \\
(1.27: 1)\end{array}$ & “ & 0.93 & 0.98 & 0.99 & $\begin{array}{l}\text { Sch. A and B samples had little to no infiltration. } \\
\text { Sch. C samples infiltrated but cracked. }\end{array}$ \\
\hline $\begin{array}{l}20-50 \% \\
(1.5: 1)\end{array}$ & "6 & 0.92 & 0.96 & 0.92 & $\begin{array}{l}\text { Little to no infiltration tor all samples. Sch. C } \\
\text { had the most infiltratic: }\end{array}$ \\
\hline $\begin{array}{l}25-40 \% \\
(1.27: 1)\end{array}$ & $\begin{array}{l}25 \% \mathrm{MoSi}_{2}-75 \% \\
\mathrm{SiC}\end{array}$ & 0.81 & 0.91 & 0.91 & $\begin{array}{l}\text { Sch. A and B samples fairly good; fine cracks } \\
\text { seen in one Sch. B sample. Sch. C samples had } \\
\text { the most cracking. }\end{array}$ \\
\hline $\begin{array}{l}25-45 \% \\
(1.27: 1)\end{array}$ & “ & 0.89 & 0.90 & 0.93 & $\begin{array}{l}\text { Good infiltration except for me Sch. C sample. } \\
\text { Some fine cracks in samp }\end{array}$ \\
\hline $\begin{array}{l}25-50 \% \\
(0.67: 1)\end{array}$ & “ & 1.35 & 1.25 & 1.45 & No infiltration except for on wh. C sample. \\
\hline $\begin{array}{l}25-50 \% \\
(1.27: 1)\end{array}$ & “ & 0.90 & 0.90 & 0.95 & $\begin{array}{l}\text { One sample from each schedule didn't infiltrate; } \\
\text { other samples were infiltrated but cracked }\end{array}$ \\
\hline $\begin{array}{l}25-50 \% \\
(1.5: 1)\end{array}$ & “ & 0.90 & 0.88 & 0.87 & $\begin{array}{l}\text { No infiltration except for one Sch. C sample } \\
\text { which had fine cracks }\end{array}$ \\
\hline $\begin{array}{c}25-55 \% \\
(1: 1) \\
\end{array}$ & “ & 1.05 & 1.01 & 1.07 & No infiltration for any samples \\
\hline $\begin{array}{l}25-60 \% \\
(1: 1)\end{array}$ & “ & 0.99 & 0.97 & 1.01 & $\begin{array}{l}\text { No infiltration except for one Sch. C sample } \\
\text { which had fine cracks }\end{array}$ \\
\hline
\end{tabular}


Table 2. Mercury porosimetry data for samples fabricated using ammonium molybdate.

VOLUME \% OF PORES IN THE INDICATED SIZE RANGE, $\mathrm{mL} / \mathrm{g}$

\begin{tabular}{|c|c|c|c|c|c|c|c|c|c|}
\hline Sample & $\begin{array}{c}\text { Open } \\
\text { Porosity } \\
(\%)\end{array}$ & 0.46 to 0.5 & 0.5 to 1 & 1 to 2 & 2 to 3 & 3 to 5 & 5 to 10 & $>10$ & Total \\
\hline $\begin{array}{l}15-50 \%(1: 1) \\
\text { Sch.A }\end{array}$ & 44.4 & 1.8 & 58.4 & 36.4 & 1.45 & 0.56 & 0.32 & 1 & 99.93 \\
\hline $\begin{array}{l}20-40 \%(1.27: 1) \\
\text { Sch.A }\end{array}$ & 52.0 & 0.14 & 3.75 & 43.2 & 48.26 & 3.43 & 0.33 & 0.84 & 99.95 \\
\hline $\begin{array}{l}20-45 \%(1.27: 1) \\
\text { Sch.A }\end{array}$ & 57.2 & 0.18 & 4.14 & 34.5 & 52.9 & 5.73 & 0.62 & 1.89 & 99.96 \\
\hline $\begin{array}{l}20-45 \%(1.27: 1) \\
\text { Sch.B }\end{array}$ & 55.4 & 0.47 & 8.27 & 78.22 & 9.45 & 0.94 & 0.57 & 2.08 & 100 \\
\hline $\begin{array}{l}20-45 \%(1.27: 1) \\
\text { Sch.C }\end{array}$ & 54.7 & 0.83 & 13.51 & 81.37 & 1.55 & 0.46 & 0.56 & 1.72 & 100 \\
\hline $\begin{array}{l}20-50 \%(1.27: 1) \\
\text { Sch. A }\end{array}$ & 53.4 & 0.3 & 5.14 & 90.65 & 2.6 & 0.39 & 0.34 & 0.5 & 99.92 \\
\hline $\begin{array}{l}25-40 \%(1.27: 1) \\
\text { Sch. A }\end{array}$ & 57.1 & 0.37 & 4.84 & 75.42 & 17.47 & 0.4 & 0.29 & 1.14 & 99.93 \\
\hline $\begin{array}{l}25-40 \%(1.27: 1) \\
\text { Sch. C }\end{array}$ & 59.4 & 0.51 & 6.73 & 75.94 & 13.39 & 1.06 & 0.69 & 1.53 & 99.85 \\
\hline $\begin{array}{l}25-45 \%(1.27: 1) \\
\text { Sch.A }\end{array}$ & 54.7 & 0 & 4.12 & 54.24 & 39.09 & 1.11 & 0.4 & 1.04 & 100 \\
\hline $\begin{array}{l}25-45 \%(1.27: 1) \\
\text { Sch. B }\end{array}$ & 57.1 & 0.42 & 5.76 & 83.68 & 8.37 & 0.47 & 0.33 & 0.97 & 100 \\
\hline $\begin{array}{l}25-45 \%(1.27: 1) \\
\text { Sch.C }\end{array}$ & 55.8 & 0.58 & 10.36 & 82.23 & 3.47 & 0.58 & 0.48 & 2.23 & 99.93 \\
\hline $\begin{array}{l}25-50 \%(1.27: 1) \\
\text { Sch.A }\end{array}$ & 50.9 & 0.33 & 8.89 & 52.48 & 33.97 & 2.23 & 0.88 & 1.16 & 99.94 \\
\hline
\end{tabular}


Table 3, Results of Molten Silicon Metal Infiltration for Samples Prepared with Molybdenum Carbide.

\begin{tabular}{|l|l|l|l|l||}
\hline $\begin{array}{l}\text { Target } \\
\text { Composition }\end{array}$ & $\begin{array}{l}\% \\
\text { Graphite* }\end{array}$ & $\begin{array}{l}\text { Slurry } \\
\text { Viscos- } \\
\text { ity }\end{array}$ & $\begin{array}{l}\text { Densit } \\
\mathbf{y} \\
\mathbf{g} / \mathbf{c c})\end{array}$ & Infiltration Results \\
\hline \hline $15 \% \mathrm{MoSi}_{2}-85 \% \mathrm{SiC}$ & 45 & 4.9 & 1.28 & Infiltrated but cracked; blue and green colors \\
\hline & 48 & N/D & 1.15 & No infiltration \\
\hline & 50 & N/D & 1.12 & No infiltration \\
\hline & 50 & 4.5 & 1.29 & Infiltrated but cracked \\
\hline & 52 & N/D & 0.95 & Outside infiltrated but center not infiltrated \\
\hline & 54 & N/D & 0.99 & Infiltrated but cracked \\
\hline & 55 & 6.9 & 1.09 & Infiltrated but cracked; blue and green colors \\
\hline & 56 & N/D & 0.92 & Outside infiltrated but center not infiltrated \\
\hline & 58 & N/D & 0.85 & Very good infiltration, no cracks \\
\hline & 58 & 14 & 1.22 & Infiltrated but cracked; blue and green colors \\
\hline & 60 & N/D & 0.89 & Almost no infiltration \\
\hline & 60 & 16.6 & 1.19 & Infiltrated but cracked; blue and green colors \\
\hline & & & &
\end{tabular}

\begin{tabular}{||l|l|l|l|l||}
\hline $20 \% \mathrm{MoSi}_{2}-80 \% \mathrm{SiC}$ & 45 & 4.1 & $\mathrm{~N} / \mathrm{D}$ & Infiltrated but cracked; bluc and green colors \\
\hline & 50 & $\mathrm{~N} / \mathrm{D}$ & 1.44 & Infiltrated but cracked \\
\hline & 55 & 5.6 & 1.26 & Infiltrated but cracked; blue and green colors \\
\hline & 58 & 13.3 & 1.35 & Infiltrated but cracked; blue and green colors \\
\hline & 60 & 11.4 & 1.34 & No infiltration \\
\hline & 62 & 11.6 & 1.27 & Infiltrated but cracked; blue and green colors \\
\hline
\end{tabular}

\begin{tabular}{||l|l|l|l|l||}
\hline $25 \% \mathrm{MoSi}_{2}-75 \% \mathrm{SiC}$ & 45 & 2.5 & 1.49 & No infiltration \\
\hline & 50 & 2.9 & 1.33 & Infiltrated but cracked \\
\hline & 55 & 4.1 & 1.43 & No infiltration \\
\hline & 58 & 8.5 & 1.49 & Infiltrated but cracked; blue and green colors \\
\hline & 60 & 7.8 & 1.43 & Infiltrated but cracked; blue and green colors \\
\hline & 62 & 11.8 & 1.39 & Infiltrated but cracked; blue and green colors \\
\hline
\end{tabular}




\section{DISTRIBUTION}

\section{Internal Distribution}

1. T. N. Tiegs, 4508 , MS 6087

2. R. J. Lauf, 4508, MS 6085

3. R. A. Bradley, 4500S, MS 6161

4. T. M. Rosseel, 4500 , MS 6138

5. D. R. Hamrin, $4500 \mathrm{~N}$, MS 6285

6. L. L. Horton, $4500 \mathrm{~S}$, MS 6132

7. T. L. Payne, 111 UNIV, MS 6499

8. C. A. Valentine, 111 UNIV, MS 6429

9. P. A. Carpenter, 4500 N, MS 6269

10. Laboratory Records, $4500 \mathrm{~N}$, MS 6285 (2)

\section{External Distribution}

11. L. Leaskey, Materials Focus, Inc., Tucson, AZ

12. Office of Scientific and Technical Information, P. O. Box 62, Oak Ridge, TN 37831(2)

13. Work for Others, DOE-ORO, ER-113, P. O. Box 2001, Oak Ridge, TN 37831

14. S. J. Barish, Department of Energy, SC-32, 19901 Germantown Rd., Germantown, MD 20874-1290

15. W. M. Polansky, Department of Energy, SC-32, 19901 Germantown Road, Germantown, MD, 20874-1290 